\title{
A Penta-Helix Approach to Collaborative Governance of Stunting Intervention In West Java Indonesia
}

\author{
Muhamad Nur Afandi ${ }^{1}$, Endah Tri Anomsari ${ }^{2}$, Alikha Novira $^{3}$, Sri Sudartini ${ }^{4}$ \\ Politeknik STIA LAN Bandung ${ }^{123}$, West Java Provincial Health Office ${ }^{4}$
}

\{m.nurafandi@poltek.stialanbandung.ac.id\}

\begin{abstract}
This paper uses a qualitative research method to explore collaborative governance in sensitive stunting interventions. It uses a Penta-helix approach to analyze the collaboration of five types of stakeholders in building stunting collaborative governance. The stakeholders include local government, community, academia, business, and media; all have participated in the Eight Actions of Stunting Convergence framework. The framework has been designed by the government to accommodate collaborative governance, but the implementation falls short of desired outcomes. Using six criteria, we analyze the quality of collaborative governance, in which the Penta-helix collaboration has met five criteria, but the participation is restricted and even disputable. The collaboration fails to meet the criteria for full engagement in the decision-making process, as non-state actors participate without more formal responsibilities. Stakeholders need to create shared values and declare a stronger commitment to quality collaborative governance.
\end{abstract}

Keywords: stunting intervention; Penta-helix approach; collaborative governance; participation

\section{Introduction}

Stunting is "the impaired growth and development that children experience from poor nutrition, repeated infection, and inadequate psychosocial stimulation" (WHO, 2015). With a prevalence of $22 \%$ globally in 2020 (WHO, n.d.), stunting becomes the attention of development practitioners and is linked to the Sustainable Development Goals (SDGs), particularly Goal 2 (Zero Hunger), Target 2.2 to "end all forms of malnutrition" including stunting and wasting among children under five years old. The prevalence of regions and countries vary, with Africa, Southeast Asia, and Eastern Mediterranean with the highest average prevalence in 2020 at $31.70 \%, 30.10 \%$, and $26.20 \%$ respectively (WHO, n.d.). These numbers are higher than the target of reducing global stunting to below $20 \%$, which drives the governments in these regions to put stunting as one of their development priorities. 
Achieving the SDGs, including stunting, requires multi-level and cross-sectoral collaborations which involve the international bodies. The importance of collaboration as a driver to achieving sustainable development is acknowledged (UN Global Impact \& Accenture, 2019). Studies support the importance of collaboration in doing development. McComb et al. (2017) find that stakeholder collaboration is advantageous in developing rural tourism. While Vrontis et al. (2021) reveal that a variety of internal and external stakeholders play an important role in the sustainable tourism.

Botero-Tovar et al. (2020) study intersectoral actions (ISA) in which health and other sectors collaborate in addressing stunting, even though the result shows that the actions are limited by administrative barriers and difficulties in engagement and communication. This shows that the success of collaboration needs the incorporation of various components throughout the collaborative process (McComb et al., 2017). Botero-Tovar et al. (2020) conclude that driving intersectoral actions need political will, motivation, and collaboration brings impact to health improvement.

With a locus of study in West Java, one of the provinces in Indonesia with a stunting prevalence as high as $31.1 \%$ in 2018 (BPS, n.d.), this paper is an exploration of the Penta-helix stakeholders' collaboration and its quality of stunting collaborative governance. As the province implements two types of stunting interventions, namely specific and sensitive intervention, this paper is focused on the latter which involves multi-level and cross-sectoral collaborations. A Penta-helix approach is used to analyze the contributions of government, private business, civil society, private business, and media to stunting intervention. The paper then proceeds to an analysis of to what extent the Penta-helix stakeholders' collaborative governance is by considering six criteria.

\section{Theoretical Framework and Context}

Stunting is a condition where children under five years old experience "the impaired growth and development that children experience from poor nutrition, repeated infection, and inadequate psychosocial stimulation" (WHO, 2015). The height of stunted children shows two standard deviations below the WHO Child Growth Standard median. The causes of stunting are multi-factors such as economic, social, the mother's nutritional status during pregnancy, illness, and the lack of nutrition. Among many possible causes, the strong predictors of stunting of children aged 0 to 23 months in Indonesia are sanitation and drinking water (Torlesse et al., 2016). Stunting causes adverse functional consequences, including poor cognitive performance, increased risk of nutritional disease, and low income and productivity as adults (WHO, 2015).

It hinders the linear growth (Schmidt, 2014), that is associated with morbidity and mortality risk, and is closely linked with child development in several domains including cognitive, linguistic, and motoric capacities (WHO, 2015). It also causes the problem of low admission rate to school, job-seeking difficulty when the children grow up, and higher risk of giving birth (Victora et al., 2008). These short and long-term effects on individual development drive governments in countries with a high prevalence of stunting to address the problem.

Indonesia has a high prevalence of stunting and consequently, puts the issue as one of the development priorities. In the country, stunting interventions are divided into two types, namely specific and sensitive interventions. Specific interventions are focused on the causes of stunting by addressing adequate nutritional intake, providing foods, treatments, and better parenting, and treating infections or illnesses. While sensitive interventions involve more than what causes 
stunting directly as they include providing better accessibility to healthy foods, improving the health service quality, increasing the awareness and commitment about stunting reduction, and increasing the provision of clean water and sanitation facility. While most specific interventions are handled by the health offices, sensitive interventions involve multi-levels and cross-sectoral collaboration.

The involvement of multi-stakeholders in development programs such as stunting interventions requires a system that accommodates the collaboration process. The concept of collaborative governance explains such an accommodating system. The idea of collaborative governance is to let actors that were previously outside the public policy process be involved, such as civil associations, private organizations, communities, and social movements. It brings public and private stakeholders to collaborative forums and aims for a consensus (Ansell \& Gash, 2008). Governance shows the relationship between civil societies (the governed) and the government (McCarney, 1996).

The actors involved in the governance of the development program are the stakeholders, referring to those who have interests and influences or being influenced by the development process (Smutko, 2008). Furthermore, Ansell and Gash (2008) stress six important criteria of collaborative governance, those are (1) the initiation of the forum comes from public organization, (2) participants include non-state actors, (3) participants are fully engaged in the decision-making process, (4) the forums and meetings are formally organized, (5) the goal is consensus, (6) the domain of collaboration is public management and policy.

\section{Research Method}

This research uses a qualitative method to explore the collaboration of Penta-helix stakeholders in sensitive stunting interventions in West Java. Data were collected through the official publication, reports, documents from the West Java Provincial Health Office, interview, and observation. Six criteria of collaborative governance as proposed by Ansel and Gash (2008) are used to analyze the quality of governance.

\section{Data and Analysis}

West Java, one of the provinces in Indonesia, prioritizes stunting intervention as the province faces a high prevalence at $31,1 \%$ in 2018 (BPS, n.d.). With a target to lower the prevalence to $14 \%$ by 2024 , the provincial government needs to drive not only specific interventions but also sensitives ones. The provincial government encourages the implementation of the Eight Actions of Stunting Convergence framework created by the Ministry of Home Affairs.

The framework aims to synergize the planning, budgeting, implementation, monitoring, and evaluation of cross-sectoral and multi-levels stunting interventions. The eight actions refer to the eight steps of the convergence: (1) situation analysis, (2) program planning, (3) stunting discussion forum, (4) regent/mayor regulation, (5) training of human development cadre, (6) system management of stunting data, (7) stunting measure and publication, and (8) annual performance review.

The organization in charge of each action is the local government bodies in each regency/city along with district and village-level governments in their respective regions, but the Penta-helix stakeholders are involved in each action. 


\section{a. Situation Analysis}

Situation analysis aims to identify the spatial pattern of stunting cases and check the currently available stunting-related services. The organization in charge is the regency/city's Development Planning Agency (BAPPEDA) with a partnership with academia to conduct the study. The result of the study is used to understand stunting case locations, recommend programs, and improve intervention delivery. This action is an effort to make stunting interventions more evidence-based, with the implementation is often restricted to local government agencies. Collaboration in conducting this action at the regency/city level is still very limited.

\section{b. Program Planning}

After situation analysis, the local agencies in West Java's cities and regencies proceed to program planning, which normally takes place in February each year. The government agencies design program plans and consults with the local legislative. The plans are then discussed and finalized, which is part of the next action. The Local Development Planning Agency $(B A P P E D A)$ is responsible to review the situation analysis and recommend other related agencies to integrate stunting interventions in their programs. The related agencies include those with a function to perform services and programs in health, housing, education, foods, water, and sanitation.

\section{c. Stunting Discussion}

Stunting discussion is an important forum for the government agencies to meet the public (community) and non-governmental actors and discuss the program plans about stunting. Through this forum, governments aim to get feedback and ideas about stunting interventions and ensure that the plans are in line with the result of village and district development planning consensus (musrenbang). Stunting discussion is formalized forum, undertaken under formal approval from the regent/mayor, and normally done before the city/regency level of musrenbang. Besides the government agencies, Penta-helix stakeholders are invited to this forum, such as civil society, academia, and non-profit organization, even though they have not been fully engaged in the discussion. By the end of the discussion, the stakeholders sign a commitment and agreement declaration to conduct stunting interventions.

\section{d. Regulation}

As per the Indonesian central government policy about village fund, a transfer directly to village level government for development purposes, villages in West Java can use the transfer to fund stunting interventions. The regent/mayor has the authority to issue a regulation about the list of village-scale local authorities and the list includes the authority to conduct stuntingrelated programs. Issuing regulation is followed by socialization. In this regulation-making process, non-governmental organizations are not normally involved, except when the regency/city government decides to involve academia to work on the academic draft of the regulation.

\section{e. Training of Human Resource Cadre}

Human resource cadre is a term used by the government to refer to people (from the local community) who are selected through village-level discussion to assist the village government in the implementation of stunting interventions. The cadre is from the respective local communities, such as those who work in the Integrated Health Service Post (posyandu) at a community level and teachers of early childhood education programs. This action is a form of community participation, in which the cadres, insiders of the community, are responsible for monitoring the stunting-related service delivery to the household with a child aged up to 1000 days, advocating and facilitating the village governments to use part of the village fund for stunting interventions, counseling and facilitating communities to be more engaged in stunting 
interventions, and bridging the community with government agencies. With these responsibilities, the cadre plays an important role in awareness-raising, therefore: the cadre gets incentives from local government bodies responsible for community empowerment and training to increase their capacity. Moreover, as this action is linked to the implementation of interventions, this stage is where private business plays a role. Private businesses contribute to the implementation of stunting interventions, in which they help with the service delivery and sponsor the cadre training.

\section{f. System Management of Stunting Data}

System management of stunting data is an important part of stunting interventions. Data is required in all levels of stunting interventions. At the village level, data is required during situation analysis and program planning. At the district level, data is important to advocate village leaders to address stunting. At the city/regency level, data is required for program planning, monitoring, and performance review. The ones responsible for data are the government agencies, with the Local Development Planning Agency (BAPPEDA) in charge as the coordinator.

\section{g. Stunting Measurement and Publication}

Stunting prevalence measurement is an action to monitor data and progress of stunting interventions. Stunting measurement is the responsibility of The Regency/City Health Office, in coordination with the Agency for Community Empowerment and Rural Development. This means that the measurements and progress monitoring are the responsibilities of the government. The publication, however, is a sharing responsibility between the government and the media. The Health Office monitor stunting measurement and analyze data, then together with the other related government bodies identifies the target audience and organizes dissemination and publication. This is where media plays a role in circulating information about stunting data and interventions.

h. Annual Performance Review

Annual performance review aims to compare the output with the initial plan of interventions. The local Secretariat and Planning Agency are responsible for the reviews. There are three points to be reviewed, those are the implementation of the Eight Actions of Stunting Convergence, the implementation of stunting-related programs, and the effectiveness of budgeting in stunting interventions. The reviews are done by the regency/city governments and the provincial governments of West Java.

The contribution of Penta-helix stakeholders in these eight actions of stunting convergence is there. In summary, the government plays the biggest role in the overall process of convergence. Academia plays a role in conducting studies regarding situation analysis and writing an academic draft for regulation and program plans. Community plays a significant role as they are involved in program planning and cadre system. Program planning and discussion also involve other non-state actors. Media contributes to the publication of stunting data and intervention evaluation and campaign. However, the contributions by non-governmental stakeholders are considered limited. The low convergence score in city/regency in West Java reflects this condition.

Convergence score is used by the West Java Provincial Government to review the implementation of the Eight Actions of Stunting Convergence in regency/city in West Java. The assessment is conducted by a team organized by the Ministry of Home Affairs and using 21 indicators. Some of those indicators are linked specifically to the collaborative governance process, such as Indicator 1.4 about coordination among government agencies and stakeholders, Indicator 3.1 about active participation by government bodies and stakeholders, Indicator 3.2 
about stunting discussion that results in a declaration of commitment, Indicator 3.3 about stunting socialization and publication, and Indicator 4.1 about stunting program facilitation, the role of civil organizations, campaign, and publication. Convergence scoring is between 0 to 4 , in which 4 is the best performing indicator. According to the evaluation result of stunting convergence in West Java's cities/regencies, from 20 regencies/cities in West Java, there are only 8 that get a score of 3 or higher during the convergence evaluation (Ministry of Home Affairs, 2021), which reflects that the eight actions of stunting convergence still have not been fully implemented.

Using the six criteria of collaborative governance by Ansell and Gash (2007), we can assess the quality of collaborative governance in stunting interventions in West Java.

(1) the initiative of collaboration comes from public agencies. This is true for collaborative governance of stunting interventions in West Java, in which collaboration initiative coming from the local executive, as a response to the mandate from central government through the Ministry of Home Affairs. The collaborative governance is also conducted under the framework of the Eight Actions of Stunting Convergence, which was designed by the Ministry of Home Affairs. As the initiative is a mandate for local executives, collaborative governance requires the participation of non-state actors to be an actual collaboration. It is important to look at other collaborative governance criteria.

(2) Participants include non-state actors. Regardless of the extent of participation, all Pentahelix actors have participated in the stunting interventions in West Java. Academia, community, private business, and media have their contributions in the process. However, Ansell and Gash (2008) emphasize how non-state actors must "have real responsibility for policy outcomes" (p. 546) and for this to happen, collaboration needs non-state actors to be fully engaged in the interventions.

(3) Participation is in form of active participation, not consultation by the government. Sensitive stunting interventions in regency/cities in West Java are difficult to meet the third criteria. Even though the convergence framework is open for stakeholders, it is difficult to encourage more active engagement from non-state actors. Stunting interventions are seen primarily as the government agenda, therefore: non-state actors have not realized their important role in collaborative governance. There is no apparent shared value and interest that drive nonstate actors to engage actively in the process. Non-state actors participate when they are invited by the government and therefore, they have no real and formal responsibilities in the convergence framework. Even though the framework is accommodating for collaborative governance, participation during stunting discussion often falls as 'consultation' category.

(4) The collaboration and meeting are formally organized. Formal collaboration distinguishes "collaborative governance" from "mode casual and conventional forms of agencyinterest group interaction" (Ansell \& Gash, 2008, p. 546). Formal collaboration shows an explicit collective strategy to achieve the agenda. This has been shown in stunting interventions in West Java, where the convergence framework is open for the public. Even though the framework was designed by the government, in its nature, it welcomes Penta-helix stakeholders' participation.

(5) Collaboration aims for consensus. This is what the program planning and stunting discussion forums are about. By the end of these two processes, Penta-helix stakeholders reach a 'consensus' and sign an agreement and commitment declaration together. In most cases in West Java, non-state actors merely agree on the programs proposed by the government, which implies that the signed agreement is not an actual consensus resulting from a more democratic process. The governance meets the fifth criteria only if we consider the signed agreement as a consensus, which is debatable. 
(6) Collaborative governance focuses on public policy and management. As the stunting interventions involve collaboration, albeit very limited, it can be said that stunting interventions have met the sixth criteria. Program planning and stunting discussion are two forums that open spaces for non-state actors to have more say in stunting-related policy and management.

Stunting convergence has offered a framework for collaborative governance at a local level. The Eight Actions of Stunting Convergence framework is designed with an initiative to encourage the Penta-helix stakeholders' participation. The low quality of collaborative governance lies in its implementation rather than its design. As the quality of collaborative governance itself is minimal if we see it from the six criteria, it is important to understand what the stakeholders need to improve. Penta-helix stakeholders, especially the non-state ones, need to realize the importance of addressing stunting and their role in the process. Creating shared values may motivate the non-state stakeholders to be fully engaged in the intervention process. This also requires their commitment to higher quality collaborative governance.

\section{Conclusion}

Collaboration in sensitive stunting interventions in West Java, which is focused on the Eight Actions of Stunting Convergence, is there. Penta-helix stakeholders are all involved in the intervention process, but their participation is restrained. This can be seen from the low score of convergence in West Java cities/regencies. This is also apparent when we apply the six criteria of collaborative governance proposed by Ansell and Gash (2007), in which the Penta-helix collaboration meets five criteria and fails to meet criteria on full engagement during the process. This shows that stunting intervention in West Java has a framework that accommodates collaborative governance, but the implementation is still far from expectation. Penta-helix stakeholders need to create shared values and commitment for higher quality collaborative governance to make the system work more effectively.

\section{References}

[1] Ansell, C., \& Gash, A. (2008). Collaborative governance in theory and practice. Journal of Public Administration Research and Theory, 18(4), 543-571. https://doi.org/10.1093/jopart/mum032

[2] Botero-Tovar, N., Arocha Zuluaga, G. P., \& Ramírez Varela, A. (2020). Factors influencing delivery of intersectoral actions to address infant stunting in Bogotá, Colombia - A mixed methods case study. BMC Public Health, 20(1). https://doi.org/10.1186/s12889-020-09057-x

[3] BPS. (n.d.). Persentase Balita Pendek Dan Sangat Pendek (Persen) . Https:/Www.Bps.Go.Id/Indikator/Indikator/View_data/0000/Data/1325/Sdgs_2/1.

[4] McCarney, P. L. (1996). Considerations on the Notion of "Governance" - New Direction for Cities In The Developing World. In P. L. McCarney (Ed.), Cities and Governance, New Direction in Latin America, Asia, and Africa (pp. 3-20). Center for Urban and Community Studies University of Toronto.

[5] McComb, E. J., Boyd, S., \& Boluk, K. (2017). Stakeholder collaboration: A means to the success of rural tourism destinations? A critical evaluation of the existence of stakeholder collaboration within the Mournes, Northern Ireland. Tourism and Hospitality Research, 17(3), 286-297. https://doi.org/10.1177/1467358415583738

[6] Ministry of Home Affairs. (2021). Peringkat Kinerja Kabupaten/Kota dalam Pelaksanakan Aksi Konvergensi Penurunan Stunting Terintegrasi Tahun 2021. Unpublished works. 
[7] Schmidt, C. W. (2014). Beyond malnutrition: The role of sanitation in stunted growth. Environmental Health Perspectives, 122(11), A298-A303. https://doi.org/10.1289/ehp.122-A298

[8] Smutko, L. S. (2008). Managing Stakeholder Involvement in Three Ordinance Development. In North Carolina Urban Forestry Conference: http://www.ncsu.edu/nrli/resources/PresentationsandWorkingPapers.php.

[9] Torlesse, H., Cronin, A. A., Sebayang, S. K., \& Nandy, R. (2016). Determinants of stunting in Indonesian children: Evidence from a cross-sectional survey indicate a prominent role for the water, sanitation and hygiene sector in stunting reduction. BMC Public Health, 16(1). https://doi.org/10.1186/s12889-016-3339-8

[10] UN Global Impact \& Accenture. (2019). The Decade to Deliver A Call to Business Action.

[11] Victora, C. G., Adair, L., Fall, C., Hallal, P. C., Martorell, R., Richter, L., \& Sachdev, S. (2008). Maternal and Child Undernutrition 2 Maternal and child undernutrition: consequences for adult health and human capital. Www.Thelancet.Com, 371. https://doi.org/10.1016/S0140

[12] Vrontis, D., Christofi, M., Giacosa, E., \& Serravalle, F. (2021). Sustainable Development in Tourism: A Stakeholder Analysis of the Langhe Region. Journal of Hospitality and Tourism Research. https://doi.org/10.1177/1096348020982353

[13] WHO. (n.d.). Stunting Prevalence among Children under 5 Years of Age (\%). Retrieved September 22, 2021, from https://www.who.int/data/gho/data/indicators/indicator-details/GHO/gho-jmestunting-prevalence

[14] WHO. (2015). Stunting in a nutshell. https:/www.who.int/news/item/19-11-2015-stunting-in-anutshell 